Mr. Abbay, the rock is limestone, as is proved by its being largely quarried and burned. Moreover, the patena soil in Ouvah is not of the ordinary worthless quality, at any rate in the opinion of planters owning portions of it, as they frequently assert that it is as good as the jungle soil of Dimbula, and the neighbouring districts. What truth there is in this I cannot say. Further, though cleared forest land when abandoned usually runs into "chena," I could show Mr. Abbay, if he were to return to Ceylon, as I wish he would, cases in which it has run into patena. The Dimbula cricket ground is a case in point.

Pendleton, Manchester, April I7

E. HEELIS

\section{Cumming's Electricity}

IN a passage from my "Introduction to the Theory of Electricity" which you quote in a review of the work in NATURE, vol. xv. p. 526 , occurs a very unfortunate misprint of the word of for the word on, which seems to have misled your reviewer, and I therefore beg a few lines to correct it. The passage in question is the statement of Prop. 8, p. 203, which ought to have been written: "In computing the potential on any closed circuit we may sub. stitute for it any closed circuit which is obtained by projecting the given circuit by means of lines of force."

In defence of this phrase I may perhaps be allowed to point out that the definition of potential quoted by the reviewer as that of Sir William Thomson is not the definition of potential but of electrostatic potential at a point, which is given at p. 45 of my book. The phrase potential on an electrified body in a field of electrical force is, I hold, perfectly legitimate, denoting the work done against electrical forces in moving the body (supposing all electrification undisturbed by the movement) to an infinite distance out of the field.

The case in point, however, refers to electro-magnetic potential and the potential on the closed circuit really represents the work done in carrying the circuit against magnetic forces out of the magnetic field.

The phrase suggested in your review-induction through the circuit-I had purposely avoided as liable to be confused with ordinary "magnetic induction" in a mass of magnetic iron, or with the "self-induction" of the circuit, or even with the induced current produced by the movement of the circuit, while the phrase potential on the circuit is at once suggestive of its own meaning and clear from any ambiguity.

Rugby, April I9

\section{CUMMing}

\section{Remarkable Papuan Skull}

I WISH to call your attention to a remarkable Papuan skull which Prof. Mantegazza showed at the last meeting of the Anthropological Society of Italy. The upper jaw contained very distinctly no less than four molars and two canine teeth on each side, all the molars being well developed.

Unfortunately the lower jaw is missing, but if it corresponded with the upper jaw, as we may justly presume--the whole skull not showing any abnormality of structure-the total number of teeth would amount to forty. There are cases recorded of negro-skulls showing three, four, and five supernumerary teeth, but eight is certainly an extremely rare occurrence.

It would be interesting to know whether museums or collections in England contain any similar specimens. J. E. Z.

\section{Meteor}

ABOUT 10.50 P.M. on the night of Monday, the I6th"inst., the sky being cloudless and the young moon just setting, I observed a remarkable meteor in the northern heavens. It originated near to the star $\gamma$ Cephei, and travelled towards the eastern horizon, its path forming an angle of about $35^{\circ}$ with the perpendicular. The head, two or three times as large and bright as Venus, was bluish, and left a trail of yellowish light. I took it at first for a falling rocket, whose ascent $I$ had not noticed; but its transient existence, its sudden extinction without noise or sparks, and the straightness of its path, with only a slight zig-zag, but no curve, preclude that explanation $I$ think.

Leicester, April 17

F. T. MotT

\section{OUR ASTRONOMICAL COLUMN}

The U.S. Naval ObSeRVatory, Washington.-Under the title "Instruments and Publications of the United States Naval Observatory," the superintendent has circulated a series of photographs of the instruments at present in use in that noble astronomical institution. They are taken by the heliotype process, and comprise (I) the mural circle, mounted in 1844, aperture $4 . \mathrm{I}$ inch; the transit instrument, 5.33 inch aperture, mounted in the same year, and placed in the same room beside the mural circle; the smaller equatorial, mounted in 1844 , with which so much good work has been performed, aperture $9^{\cdot 62}$ inch; the transit-circle, by Pistor and Martins, Berlin, which was mounted in 1866 , the aperture of the object-glass 8.52 inch, and the focal length $I 2$ feet $\mathbf{I}$ inch; a general view of the grand 26-inch refractor, of 32 feet 5.8 inch focal length, mounted in 1873, and one of the most powerful telescopes in the world; the clock-work, \&c., of this magnificent instrument is shown on a separate plate. Brief descriptions accompany these heliotypes, and in addition are drawings made with the 26 -inch equatorial of the nebula in Orion, the omega nebula, the annular nebula in Lyra, and the planet Saturn. Some account of the foundation of the observatory and a list of its publications from I $845-76$ precede the brief description of the instruments of which views are presented.

NEW VARIABLE STAR. - A recent number of M. Leverrier's Bulletin International contains a notice from MM. Henry respecting a variable star in Virgo, which they state has been under observation for some time. The period is about seven months, and the limits of variation $8 \mathrm{~m}$. to $14 \mathrm{~m}$.; at present it is near a maximum. The position for $1877^{\circ} \mathrm{O}$ is in R.A. $12 \mathrm{~h} .27 \mathrm{~m} .32 \cdot 2 \mathrm{~s}$. , N.P.D. $93^{\circ} 44^{\prime} 37^{\prime \prime}$.

Early Observation of Solar Spots.-In our popular astronomical works the Chinese are not usually credited with the observation of spots upon the sun at a distant date. Gaubil, however, records from the Chinese annals that on May $7,82.6$ black spots were seen on the sun's disc, and again on April 2I, 832. There are, indeed, few phenomena which are not noted by this observant people, or rather by their watchful astrono. mers; yet, strange to say, the zodiacal light is amongst them. And it is singular that while Kepler's star of 1604 is duly recorded, the Chinese annals have no reference to the similar object in 1572 , with which the name of Tycho Brahe is commonly associated.

COMET 1877 Ill.-WThe comet discovered by M. Borelly at Marseilles, on April I4, appears to have been detected three or four nights earlier by Mr. Lewis Swift, of Rochester, New York, who is already the independent discoverer of more than one of these bodies. We say three or four nights earlier, for although the telegram forwarded to Europe through the Smithsonian Institution dates the observation on the night of April I I, the rough place there assigned agrees more nearly with the computed position for the previous midnight. In circular No. xxv. of the Imperial Academy of Sciences at Vienna, are elements by Dr. Holetschek, from the first three nights' observations, which it is remarked have "a very great resemblance to those of the comet of the year I762." The following orbit has been calculated by Mr. Hind from the first complete observation at Marseilles, on April r4, one at Mannheim by Prof. Schönfeld, on the I $\sigma^{\mathrm{th}}$, and a third at the observatory of Mr. J. Gurney Barclay, at Leyton, on the rgth. For the sake of comparison the elements of the comet of $\mathbf{r} 762$, calculated by Burckhardt, after a new reduction of the Paris observations, are annexed. COMET 1877 III. COMET 1762. Perihelion Passage (G.M.T.) ... April 26.950I May 28.3345

Long. of Perihelion .... Iํ. '́

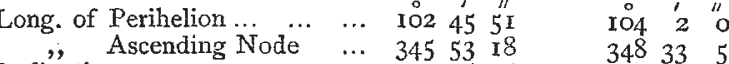

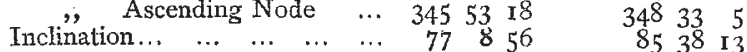

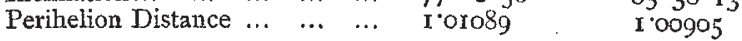
The motion is direct. It will be remarked that the only material difference is in the inclination of the orbits to the ecliptic. The comet of 1762 was discovered in the Netherlands, by Klinken. 